\title{
Amniotic Membrane Transplantation for Persistent Epithelial Defects and Ulceration due to Pseudomonas Keratitis in a Rabbit Model
}

\author{
Mohammad Mehdi Soltan Dallal ${ }^{1,2}, \mathrm{PhD}$; Farhad Nikkhahi ${ }^{3}, \mathrm{PhD}$; Seyed Mostafa Imeni ${ }^{4}, \mathrm{PhD}$ \\ Saber Molaei ${ }^{5}$, MD; Seyed Kazem Hosseini ${ }^{6}$, MS; Zohreh Kalafi ${ }^{2}$, MS; Sara Sharifi Yazdi ${ }^{7}$, MD \\ Hedroosha Molla Agha Mirzaei ${ }^{8}$, MS \\ ${ }^{1}$ Division of Microbiology, Department of Pathobiology, School of Public Health, Tehran University of Medical Sciences (TUMS), \\ Tehran, Iran \\ ${ }^{2}$ Food Microbiology Research Center, Tehran University of Medical Sciences, Tehran, Iran \\ ${ }^{3}$ Medical Microbiology Research Center, Qazvin University of Medical Science, Qazvin, Iran \\ ${ }^{4}$ Biodiversitat, Ecología, Technologia Ambiental i Alimentaria )BETA Tech Center(, (TECNIO Network), U Science Tech, \\ University of Vic-Central University of Catalonia, Carrer de la Laura 13, 08500 Vic, Spain \\ ${ }^{5}$ AJA University of Medical Sciences, Tehran, Iran \\ ${ }^{6}$ Quality Control Manager of Iranian Tissue Bank Research \& Preparation Center, Director of Stem Cells Preparation Unit, \\ Tehran University of Medical Sciences, Tehran, Iran \\ ${ }^{7}$ School of Medicine, Tehran University of Medical Sciences (TUMS), Tehran, Iran \\ ${ }^{8}$ Food Microbiology Research Center, Tehran University of Medical Sciences, Tehran, Iran \\ ORCID: \\ Mohammad Mehdi Soltan Dallal: https://orcid.org/0000-0002-3421-3974
}

\section{Abstract}

Purpose: The use of amniotic membrane has been suggested in the treatment of infectious keratitis for its intrinsic anti-infective properties probably mediated by its antiinflammatory effects. The aim of this study was to investigate the effect of amniotic membrane transplantation (AMT) along with ciprofloxacin to cure the primary stages of Pseudomonas keratitis.

Methods: In total, 28 rabbits were selected and divided in four groups as follows: group 1 as control, group 2 with amniotic membrane, group 3 with ciprofloxacin, and group 4 with amniotic membrane combined with ciprofloxacin. About $0.05 \mathrm{cc}$ suspension of Pseudomonas aeruginosa, 27853 ATCC was injected into corneal stroma.

Results: The results showed groups of AMT, AMT + ciprofloxacin, and ciprofloxacin had $0 \%$ perforation while the control group had $85.6 \%$. Average infiltration of $5.5 \mathrm{~mm}$ was observed in ciprofloxacin group, $5 \mathrm{~mm}$ in AMT + ciprofloxacin group, $24 \mathrm{~mm}$ in AMT group, and finally $23.75 \mathrm{~mm}$ for control. Amniotic membrane showed to be effective in prevention of cornea perforation as well as remission of Pseudomonas keratitis. There was no significant difference between ciprofloxacin groups in comparison with ciprofloxacin + AMT group. However, regarding the anti-inflammatory effect, the process of improvement of inflammation in ciprofloxacin + AMT group was faster.

Conclusion: Transplantation of amniotic membrane in the primary stages of Pseudomonas keratitis treatment remarkably prevents the disease and it can be used to control its process.

Keywords: Ciprofloxacin; Human Amniotic Membrane; Keratitis; Pseudomonas aeruginosa; Rabbit

J Ophthalmic Vis Res 2021; 16 (4): 552-557 


\section{INTRODUCTION}

Human amniotic membrane (AM) forms the inner wall of the membranous sac that surrounds and protects the embryo during gestation. It consists of a single layer of ectodermally derived columnar epithelial cells attached to a basement membrane with an underlying layer of mesenchyme. ${ }^{[1]}$ Amniotic membrane transplantation (AMT) is widely used in various ocular surface diseases such as neurotrophic keratitis and persistent epithelial defects, ${ }^{[2,3]}$ band keratopathy, ${ }^{[4]}$ bullous keratopathy, ${ }^{[5,6]}$ after excimer laser photorefractive keratectomy, ${ }^{[7,8]}$ after the excision of a conjunctival mass, ${ }^{[9,10]}$ pterygium, ${ }^{[11,12]}$ ocular surface reconstruction in symblepharon, ${ }^{[13,14]}$ acute chemical injury, ${ }^{[15,16]}$ and a chronic limbal deficiency. ${ }^{[17,18]}$ When used as a graft (epithelial side up), AM is expected to become incorporated in the recipient tissue. If it is used as a patch (epithelial side down), it works as a biological bandage affording a cover for a limited duration or a combination of these. The use of AM has been also suggested in the treatment of infectious keratitis because of its intrinsic anti-infective properties probably mediated by its anti-inflammatory effects and because AM may act as a long-term drug delivery system. ${ }^{[19-21]}$ The antimicrobial effects of AM have been demonstrated against several species such as Escherichia coli, Group A Streptococci, Pseudomonas aeruginosa, and Staphylococcus aureus. $^{[22,23]}$ AM graft for epithelial reformation has been employed in order to eradicate the $P$. aeruginosa infection of keratitis and have exhibited desirable outcomes. ${ }^{[24]}$

The aim of the current study was to investigate the effect of AMT along with ciprofloxacin to cure the primary stages of Pseudomonas keratitis.

\section{Correspondence to:}

Mohammad Mehdi Soltan Dallal, PhD. Food Microbiology Research Center (FMRC)/Division of Food Microbiology, Department of Pathobiology, School of Public Health, Tehran University of Medical Sciences (TUMS), Tehran 6446-14155, Iran.

E-mail: soltanda@sina.tums.ac.ir/ msoltandallal@gmail.com

Received: 13-11-2020 Accepted: 21-05-2021

Access this article online

Website: https://knepublishing.com/index.php/JOVR

DOI: 10.18502/jovr.v16i4.9744

\section{METHODS}

All experiments were carried out in accordance with the UK Animals (Scientific Procedures) Act, 1986 and associated guidelines, EU Directive 2010/63/EU for animal experiments. In addition, this study is certified by accreditation research ethics national committee with issue code of IR.TUMS.REC.1394.2091.

In total, 28 male rabbits with an average weight of $1.5-2 \mathrm{~kg}$ were selected. The AM was prepared according to Song and Kim method. ${ }^{[25]}$ Human placenta was obtained after an elective caesarean section in a woman who was seronegative for human immunodeficiency virus, hepatitis $B, C$, and syphilis. Under a lamellar flow hood, the placenta was first washed free of blood clots with sterile saline. The inner AM was separated from the rest of the chorine by blunt dissection and flattened onto a nitrocellulose membrane. ${ }^{[26]}$ The membrane with the filter was then washed three times with phosphate buffered saline (PBS) containing 50 $\mathrm{\mu g} / \mathrm{ml}$ penicillin, $50 \mu \mathrm{g} / \mathrm{ml}$ streptomycin, and 2.5 $\mu \mathrm{g} / \mathrm{ml}$ amphotericin B and put in M199 culture for 24 hr with antibiotic solution including streptomycin, cloxacillin, ceftriaxone, and amphotericin B, and finally packed in pieces of $1.5 \times 1.5$ in three of sterilized nylon and stored in $-80^{\circ} \mathrm{C}$ in freezer. Twenty-eight rabbits were divided into four groups as follows: group 1 as control group [Figure 1A], group 2 as AM [Figure 1-B], group 3 as ciprofloxacin [Figure $1 \mathrm{C}$ ], and group 4 as $\mathrm{AM}$ combined with ciprofloxacin [Figure 1D].

The rabbits were anesthetized with intramuscular injection of ketamine hydrochloride $(30 \mathrm{mg} / \mathrm{kg})$ and xylazine hydrochloride $(5 \mathrm{mg} / \mathrm{kg})$ and then a drop of tetracaine $\mathrm{HCL} 0.5 \%$ was applied to the rabbits' right eye. About $0.05 \mathrm{cc}$ suspension of $P$. aeruginosa 27853 ATCC was injected into corneal stroma with a sterile $30 \mathrm{G}$ needle connected to a micro-syringe, using an operating microscope. The experimental keratitis was allowed to proceed untreated for $20 \mathrm{hr}$. There

This is an open access journal, and articles are distributed under the terms of the Creative Commons Attribution-NonCommercial-ShareAlike 4.0 License, which allows others to remix, tweak, and build upon the work non-commercially, as long as appropriate credit is given and the new creations are licensed under the identical terms.

How to cite this article: Soltan Dallal MM, Nikkhahi F, Imeni SM, Molaei S, Hosseini SK, Kalafi Z, Yazdi SS, Mirzaei HMA. Amniotic Membrane Transplantation for Persistent Epithelial Defects and Ulceration due to Pseudomonas Keratitis in a Rabbit Model. J Ophthalmic Vis Res 2021;16:552-557. 
was no interference in the control group. In groups 3 and 4 , the $A M$ in pieces of $1.5 \times 1.5 \mathrm{~cm}$ transplanted to the entire corneal surface by eight interrupted 10.0 nylon sutures. On the first day, ciprofloxacin drop was injected to groups 2 and 4 every 30 min.

On the second day to seventh day every $2 \mathrm{hr}$, the results were registered in aspect of perforation in cornea and the amount of infiltration by the use of image $J 1$ software.

\section{RESULTS}

Results were registered as clinical reports on the first, third, and seventh day [Table 1]. During the first $20 \mathrm{hr}$, after injecting $P$. aeruginosa, a white opacity appeared in all rabbits. Rabbits had corneal ulcers and on the second day, the conjunctiva was markedly hyperemic in four groups. At the end of the first week, Hypopyon formation was noticed in five eyes in the AMT group. Corneal perforation was noticed in four cases in the control group but in no case in other groups.

The results showed that the cornea had infiltration in which central part, an area with the size of $6 \mathrm{~mm}$ had descemeto cell and progress toward causing perforation in cornea control group (A: Control group). On the other hand, AMT group conjunctiva inflammation showed to be less than control group and in cornea examination the amount of infiltration showed to be $24 \mathrm{~mm}$ (B: AMT group). For ciprofloxacin group, ciprofloxacin sediment was clearly visible (C: ciprofloxacin) and finally in the group with ciprofloxacin + AMT as well as the ciprofloxacin group the decrease of opacity cornea was quite visible (D: AMT + ciprofloxacin).

The clinical results of four groups in examination of Pseudomonas keratitis are also shown in Table 2. These results showed that AMT + ciprofloxacin group had $0 \%$ perforation and the control group had $85.7 \%$. Average infiltrations were $5 \mathrm{~mm}$ in AMT + ciprofloxacin groups and $23.75 \mathrm{~mm}$ in control.

The result showed that the AMT, ciprofloxacin, and $\mathrm{AMT}+$ ciprofloxacin were effective on perforation and infiltration on all groups compared to the control group.

In addition, there was no significant difference between ciprofloxacin group and ciprofloxacin combination with AM. In the same way, there was no significant difference between membrane amniotic group and ciprofloxacin compared with combined group of ciprofloxacin with membrane amniotic.

\section{DISCUSSION}

Few studies have investigated the effect of AMT in the surgical treatment of severe infectious keratitis with corneal ulceration or perforation. ${ }^{[19,23,27]}$ The main advantages of AMT in the treatment of bacterial keratitis that we observed are the epithelial bandage properties, which allowed early use of topical steroids; the anti-inflammatory and anti-scarring effects of the $A M$, the promotion of epithelialization, and the possible benefits of a direct antimicrobial role of the AM. ${ }^{[28]}$ These studies found AMT to be effective in treating neurotrophic ulcer, inflammatory corneal ulcer, bullous keratopathy, inflammatory or noninflammatory scleral ulcer and as an adjuvant treatment of pterygium excision. The basement membrane of an AM promotes epithelial growth and differentiation, reinforces the adhesion of basal epithelial cells and prevents epithelial apoptosis. The stroma matrix suppresses TGFb signaling, proliferation, and myofibroblastic differentiation of normal human corneal and limbal fibroblasts and thus, inhibiting the unwanted production of extracellular matrix and scarring. ${ }^{[6]}$ These properties have made the $A M$ an ideal reconstructive substrate for repairing persistent epithelial defects and corneal ulcers, ${ }^{[2]}$ conjunctival defect, ${ }^{[9,10]}$ chemical or thermal injury, ${ }^{[15,29]}$ and limbal cell deficiency. ${ }^{[16,17]}$ The application of $A M$ in the treatment of corneal perforation and scleromalacia has been also reported. ${ }^{[30,31]}$ The human AM possesses anti-inflammatory, antifibrotic, and antiangiogenic properties, and these attributes make it ideal for ocular surface reconstruction procedures. ${ }^{[32,33]}$ In addition, the $A M$ also has antimicrobial properties due partly to its anti-inflammatory effects, and also due to secretion of elfin and secretory leucocyte proteinase inhibitor, both of which have antimicrobial actions and act as components of the innate immune system. ${ }^{[34,35]}$ It also contains cystatin $E$, an analogue of cysteine proteinase inhibitors, which has complementary antiviral properties. ${ }^{[36]}$ Furthermore, AM transplantation (AMT) is reserved for cases of postinfectious ulcers after an appropriate period of anti-infective treatment when clinical signs are improving. ${ }^{[37]}$ This is because the anti-infective properties of $\mathrm{AM}$ are nonspecific and not considered to be potent enough to be effective in acute infective keratitis. This is the reason behind the concept 


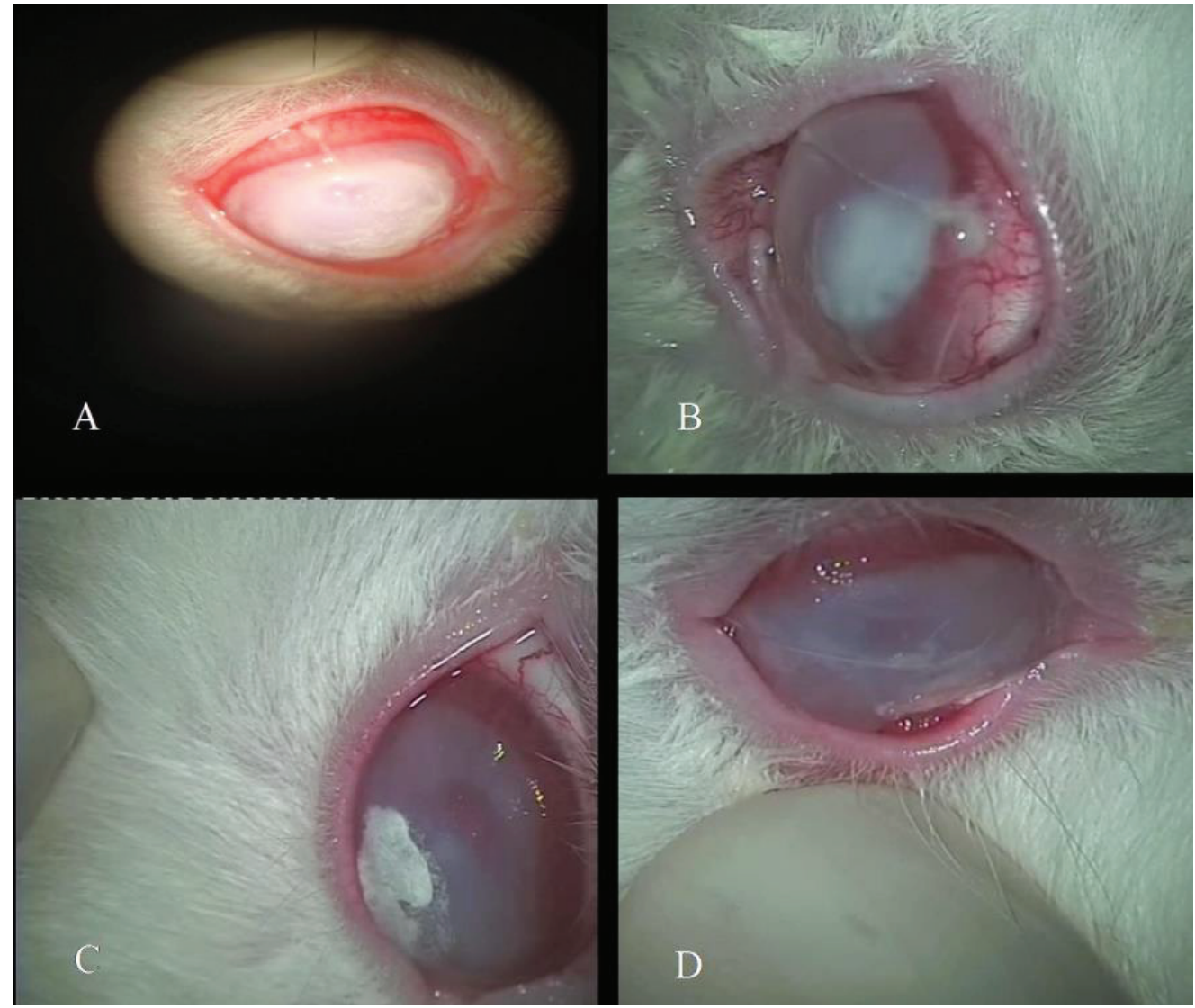

Figure 1. Cornea infiltration of the four groups of experiment. (A: Control group; B: AMT group; C: ciprofloxacin; D: AMT + ciprofloxacin).

Table 1. Clinical results of four groups on the first, third, and seventh day and in the first $20 \mathrm{hr}$ *

Groups/days

Control

AMT

ciprofloxacin

ciprofloxacin + AMT

\section{First day}

Average infiltration $2.25 \mathrm{~mm}$ with corneal opacity and without epithelial defect

Average infiltration $2.62 \mathrm{~mm}$ and without epithelial defect

Average infiltration $2.35 \mathrm{~mm}$ and without epithelial defect

Average infiltration $2.6 \mathrm{~mm}$ and without epithelial defect
Third day

Average infiltration $7.01 \mathrm{~mm}$ with corneal opacity, epithelial defect, and descemeto cell

Average infiltration $6.25 \mathrm{~mm}$ and without epithelial defect

Average infiltration $4.51 \mathrm{~mm}$ and epithelial defect

Average infiltration $4 \mathrm{~mm}$ and without epithelial defect
Seventh day

Average infiltration $23.75 \mathrm{~mm}$ with corneal opacity and epithelial defect

Average infiltration $24 \mathrm{~mm}$ and without epithelial defect, melting, and scar

Average infiltration $5.5 \mathrm{~mm}$, epithelial defect, and scar with diameter $2.5 \times 2.5 \mathrm{~mm}$

Average infiltration $5 \mathrm{~mm}$ and without epithelial defect and scar

*Findings in the first 20 hours only the first day for all groups

**AMT, amniotic membrane transplantation

of fortifying $A M$ with antimicrobial drugs to make it a viable therapeutic modality in the setting of active infections of the cornea. Antibioticimpregnated medical devices such as catheters, bone and cardiac implants have been in use for over a decade. ${ }^{[22,38]}$ Various studies have shown the potential of such an approach, for example, in vascular surgery and arthroplasty, where they appear effective in reducing the risk of bloodstream infections or in limiting deep wound infections. ${ }^{[39,40]} \mathrm{AM}$ is effective in remission of Pseudomonas keratitis and prevention of 
Table 2. Clinical outcomes of perforation and infiltration in all four groups of Pseudomonas keratitis

\begin{tabular}{lcccc}
\hline Results & AMT* $^{*}$ & AMT + ciprofloxacin & ciprofloxacin & Control \\
\hline Perforation & $(0 \%) 0$ & $(0 \%) 0$ & $(0 \%) 0$ & $(85.7 \%) 6$ \\
Infiltration & $24 \mathrm{~mm}$ & $5 \mathrm{~mm}$ & $5.5 \mathrm{~mm}$ & $23.75 \mathrm{~mm}$ \\
$\begin{array}{l}\text { Significant difference compared to } \\
\text { control group }(P \text {-value) }\end{array}$ & $P<0.5$ & $P<0.5$ & 0.5 & - \\
\hline
\end{tabular}

${ }^{*}$ AMT, amniotic membrane transplantation

cornea perforation and controlling as well as antiPseudomonas effects. There was no difference between ciprofloxacin group in comparison with ciprofloxacin + AMT group. However, regarding anti-inflammatory effects, the process of improvement of inflammation in ciprofloxacin + AMT group was faster. During this research, we came to conclusion that transplantation of $A M$ in the primary stages of Pseudomonas keratitis treatment remarkably prevents the disease and it can be used to control its process.

\section{Acknowledgements}

This work was supported by a Vice-Chancellor for Research grant (no. 10793) and approved by the Committee for Research Ethics (no.IR.TUMS.RES.1394.2091) of Tehran University of Medical Sciences (Tehran, Iran).

\section{Financial Support and Sponsorship}

Nil.

\section{Conflicts of Interest}

There are no conflicts of interest.

\section{REFERENCES}

1. Marino T. Ultrasound abnormalities of the amniotic fluid, membranes, umbilical cord, and placenta. Obs Gynecol Clin North Am 2004;31:177-200.

2. Mastropasqua L, Massaro-giordano G, Nubile M, Sacchetti $M$. Understanding the pathogenesis of neurotrophic keratitis: the role of corneal nerves. Cell Physiol 2016;September:717-724.

3. Remigio L, Leonidas T. Accelerated collagen cross-linking in the management of advanced Acanthamoeba keratitis. J Arq Bras Oftalmol 2019;8:103-106.

4. Weng S, Jan R, Chang C, Wang J, Su S. Risk of band keratopathy in patients with end-stage renal disease. Sci Rep 2016;6:28675.
5. Stefan P, Sanziana I, Liliana V, Costin L, Vanessa P, Ciuluvica R. Pseudophakic bullous keratopathy. Rom J Ophthalmol 2017;61:90-94.

6. Tonti E. Different graft thicknesses after Descemet stripping endothelial keratoplasty for bullous keratopathy in the two eyes of the same patient. Int Med Case Rep J 2019:55-59.

7. Mifflin MD, Mortensen XM. Intraoperative optical pachymetry in photorefractive keratectomy. J Cart Refract Surg 2018;45:495-500.

8. Ehlke GL, Krueger RR. Laser vision correction in treating myopia. Asia-Pacific J Ophthalmol 2016;5:434-437.

9. Palamar M, Yaman B, Akalin T, Yagci A. Amniotic membrane transplantation in surgical treatment of conjunctival melanoma: long-term results. Turkish $\mathrm{J}$ Ophthalmol 2018;48:15-18.

10. Asoklis RS, Damijonaityte A, Butkiene L, Makselis A, Petroska D, Pajaujis M, et al. Ocular surface reconstruction using amniotic membrane following excision of conjunctival and limbal tumors. Eur $J$ Ophthalmol 2011;21:552-558.

11. Kaufman SC, Jacobs DS, Lee WB, Deng SX, Rosenblatt MI, Shtein RM. Options and adjuvants in surgery for pterygium. Ophthalmology 2013;120:201-208.

12. Mitomycin C. Comparison of three methods for the treatment of pterygium: amniotic membrane graft, conjunctival autograft and conjunctival autograft plus. Int J Orbital Disord Oculoplastic Lacrimal Surg 2007;26:5-13.

13. Gündüz K, Uçakhan $O O$, Kanpolat A, Günalp I. Nonpreserved human amniotic membrane transplantation for conjunctival reconstruction after excision of extensive ocular surface neoplasia. Eye 2006;20:351-357.

14. Grewal DS, Mahmoud TH. Dehydrated allogenic human amniotic membrane graft for conjunctival surface reconstruction following removal of exposed scleral buckle. Ophthalmic Surg Lasers Imaging Retina 2016;47:948-951.

15. Tamhane A, Vajpayee RB, Biswas NR. Evaluation of amniotic membrane transplantation as an adjunct to medical therapy as compared with medical therapy alone in acute ocular burns. Ophthalmology 2005;112:19631969.

16. Pereira Gomes JA, dos Santos MS, Cunha MC, Mascaro VLD, de Nadai Barros J, Barbosa de Sousa L. Amniotic membrane transplantation for partial and total limbal stem cell deficiency secondary to chemical burn. Ophthalmology 2003;110:466-473.

17. Torabi T, Abroun S. Amniotic fluid, an effective factor for umbilical cord blood hematopoietic stem cells in cell 
culture: an approach for bone marrow transplantation. Transfus Apher Sci 2019;58:169-173.

18. Tejwani S, Kolari RS, Sangwan VS, Rao GN. Role of amniotic membrane graft for ocular chemical and thermal injuries. Cornea 2007;26:21-26.

19. Nubile M, Carpineto P, Lanzini M, Ciancaglini M, Zuppardi E, Mastropasqua L. Multilayer amniotic membrane transplantation for bacterial keratitis with corneal perforation after hyperopic photorefractive keratectomy: case report and literature review. J Cataract Refract Surg 2007;33:1636-1640.

20. Gicquel J, Bejjani RA, Ellies P. Amniotic membrane transplantation in severe bacterial keratitis. Cornea 2007;26:27-33.

21. Heidarzadeh S, Ghasemian A, Kalafi Z, Nikkhahi F, Soltan MM. Antimicrobial effects of amniotic membrane on some bacterial strains. Immunopathol Persa 2018;4:1-5.

22. Mehdi M, Soltan-Dallal M, Nikkhahi F, Molaei S, Hosseini $\mathrm{K}$, Kazem $\mathrm{M}$, et al. Effect of Amniotic membrane combined with ciprofloxacin in curing the primary stages of pseudomonal keratit. J Med Bacteriol 2012;1:31-37.

23. Kim HK, Park HS. Fibrin glue-assisted augmented amniotic membrane transplantation for the treatment of large noninfectious corneal perforations. Cornea 2009;28:170176.

24. Chen HC, Tan HY, Hsiao CH, Huang SCM, Lin KK, Ma DHK. Amniotic membrane transplantation for persistent corneal ulcers and perforations in acute fungal keratitis. Cornea 2006;25:564-572.

25. Kim SJ, Song CH, Sung HJ, Yoo YD, Geum DH, Park SH, et al. Human placenta-derived feeders support prolonged undifferentiated propagation of a human embryonic stem cell line, SNUhES3: comparison with human bone marrowderived feeders. Stem Cells Dev 2007;16:421-428.

26. Miller DD, Simmons NL, Stewart MW. Recurrent corneal erosion: a comprehensive review. Clin Ophthalmol 2019;13:325-335.

27. Bouchard CS, John T. Amniotic membrane transplantation in the management of severe ocular surface disease: indications and outcomes. Ocul Surf 2004;2:201-211.

28. Dua HS, Gomes JAP, King AJ, Maharajan VS. The amniotic membrane in ophthalmology. Diagnostic Surg Tech 2004:49:51-77.

29. Dogan C, Sevki O, Akif A, Burak O. Efficacy of fixation of the amniotic membrane on a symblepharon ring with continuous suturing in acute ocular chemical burn patients. Int Ophthalmol 2019;39:2103-2109.

30. Hanada K, Shimazaki J, Shimmura S, Tsubota K. Multilayered amniotic membrane transplantation for severe ulceration of the cornea and sclera. Am J Ophthalmol 2001;131:324-331.

31. Jeoung J, Yoon Y, Lee J. The effect of amniotic membrane transplantation on the treatment of necrotizing scleritis after pterygium excision. $J$ Korean Ophthalmol Soc 2004;45:1981-1988.

32. Azuara-blanco A, Pillai CT, Dua HS. Amniotic membrane transplantation for ocular surface reconstruction. $\mathrm{Br} J$ Ophthalmol 1999;83:399-402.

33. Sangwan VS, Burman S, Tejwani S, Mahesh SP, Murthy R. Amniotic membrane transplantation: a review of current indications in the management of ophthalmic disorders. Indian J Ophthalmol 2007;55:251-260.

34. Niknejad H, Peirovi H, Jorjani M, Ahmadiani A, Ghanavi J, Seifalian $\mathrm{M}$, et al. Properties of the amniotic membrane for potential use in tissue engineering. Eur Cells Mater 2008;15:88-99.

35. King AE, Paltoo A, Kelly RW, Sallenave J, Bocking AD, Challis JRG. Expression of natural antimicrobials by human placenta and fetal membranes. Placenta 2007;28:161-169.

36. Nguyen Lunde $\mathrm{N}$, Haugland $\mathrm{M}$, Broe $\mathrm{K}$, Larsen $\mathrm{B}$, Damgaard I, Pettersen SJ, et al. Glycosylation is important for legumain localization and processing to active forms but not for cystatin E/M inhibitory functions. Biochimie 2017;139:27-37.

37. Soltan-dallal MM, Kalafi Z, Rastegar-lari A, Hosseini SK, Rahimi-foroushani $A$. The effect of reduced bacterial dilution on human amniotic membrane antibacterial activity, in vitro. Zahedan J Res Med Sci 2013;15:6-8.

38. Quarello F, Forneris G, Borca M, Pozzato M. Do central venous catheters have advantages over arteriovenous fistulas or grafts? J Nephrol 2006;19:265-279.

39. Kowalewski M, Pawliszak W, Zaborowska K, Navarese EP, Szwed A. Gentamicin-collagen sponge reduces the risk of sternal wound infections after heart surgery: meta-analysis. J Thorac Cardiovasc Surg 2015;149:16311640.e6.

40. Harron K, Mok Q, Hughes D, Muller-pebody B, Parslow R. Generalisability and cost-impact of antibiotic-impregnated central venous catheters for reducing risk of bloodstream infection in paediatric intensive care units. PLoS One 2016;11:e0151348.5. 